\title{
A REFORMA AGRÁRIA COMO INSTRUMENTO DE JUSTIÇA DISTRIBUTIVA NOS MOLDES PROPOSTOS POR JOHN RAWLS
}

\author{
Horácio de Miranda Lobato Neto*
}

\section{RESUMO}

Analisa a Teoria da justiça proposta por John Rawls, especialmente a sua compreensão sobre justiça distributiva. Investiga se a reforma agrária pode ser entendida como um instrumento de realização dessa justiça distributiva, sobretudo em razão de sua fundamentalidade, da função social da propriedade e dos meios dispostos na legislação para a sua implementação. A metodologia adotada quanto ao procedimento foi a pesquisa bibliográfica e legislativa. Ao final, concluiu-se que a reforma agrária tem a capacidade de ressignificar o conceito de propriedade, objetiva contribuir para o desenvolvimento nacional, com a diminuição da pobreza e desigualdades sociais e por isso está alinhada à noção de justiça distributiva nos moldes do pensamento liberal igualitário de John Rawls.

Palavras-chave: Rawls; Justiça distributiva; Reforma agrária.

\section{AGRARIAN REFORM AS AN INSTRUMENT OF DISTRIBUTIVE JUSTICE IN THE MOLDS PROPOSED BY JOHN RAWLS}

\begin{abstract}
It analyzes the theory of justice proposed by John Rawls, especially his understanding of distributive justice. It investigates, from this, whether agrarian reform can be understood as an instrument for the realization of this distributive justice, mainly because of its fundamentality, the social function of property and the means available in the legislation for its implementation. The methodology adopted for the procedure was the bibliographical and legislative research. In the end, it was concluded that agrarian reform has the capacity to resignify the concept of property, aims to contribute to national development, reducing poverty and social inequalities and is therefore aligned with the notion of distributive justice along lhe lines of John's egalitarian liberal thinking Rawls.
\end{abstract}

Keywords: Rawls; Distributive justice; Land reform.

\footnotetext{
* Juiz de Direito do Tribunal de Justiça do Pará e mestrando em Direito, na área de concentração Direitos Humanos, linha de pesquisa Direitos Humanos e Meio Ambiente, pelo Programa de Pós-Graduação em Direito do Instituto de Ciências Jurídicas da Universidade Federal do Pará.
} 


\section{INTRODUÇÃO}

Considerando a desordem fundiária brasileira, a concentração de grandes áreas de terra nas mãos de poucos, a violência no campo ${ }^{1}$, o processo de grilagem e o desmatamento de grandes áreas verdes, verifica-se, de forma cada vez mais clara, a necessidade de se levar a efeito o comando constitucional da reforma agrária.

Nesse sentido, o tema proposto para o presente trabalho é o de analisar em que medida a política de reforma agrária, com assento constitucional, favorece uma noção de justiça distributiva nos moldes do pensamento liberal igualitário de John Rawls. Propõe-se, assim, o seguinte problema de pesquisa: a reforma agrária no Brasil, da maneira como está disposta sua disciplina constitucional e infraconstitucional, pode ser encarada como um instrumento de justiça distributiva, conforme o modelo proposto por Rawls?

A abordagem iniciará com o estudo a respeito da Teoria de Justiça como equidade elaborada por John Rawls, a partir da obra Uma Teoria da Justiça, mais especialmente a sua compreensão a respeito da justiça distributiva, isto é, o que Estado deve aos cidadãos. $\mathrm{Na}$ seção seguinte, será analisado o instituto da reforma agrária, sua previsão constitucional e legal. Na última parte, reservada às considerações finais, será apresentado o resultado obtido com a pesquisa.

Optou-se por utilizar a teoria Rawlsiana por ela professar um liberalismo qualificado pela igualdade, onde o sentido é de se compartilhar socialmente os bens produzidos por toda a população sem ofender a liberdade individual e por ela se preocupar, dentre outras coisas, com a distribuição de renda.

Além da reforma agrária e da concepção de justiça de Rawls, também serão abordadas a noção de justiça social como equivalente à justiça distributiva, função social da propriedade e a desapropriação por interesse social para fins de reforma agrária.

A metodologia adotada foi a pesquisa bibliográfica e legislativa. Buscou-se refúgio evidentemente na obra Uma Teoria da Justiça, de John Rawls, além das produções de estudiosos da filosofia contemporânea como Samuel Fleischacker, Roberto Gargarella e Will Kymlicka.

\footnotetext{
${ }^{1}$ Segundo dados da Comissão Pastoral da Terra (CPT), no ano de 2016 foram registrados no Brasil 1.295 conflitos de terra, que atingiram 686.735 pessoas. Disponível em: www.cptnacional.org.br. Acesso em 24/03/2018.
}

Rev. de Direito Agrário e Agroambiental | e-ISSN: 2526-0081 | Salvador | v. 4 | n. 1 | p. 56- 76 | Jan/Jun. 2018 
Acredita-se que a importância deste artigo revela-se não apenas na apresentação de uma análise sobre a concepção de justiça como equidade de John Rawls, mas também pelo fato de que discutirá, à luz do comando constitucional e das orientações infraconstitucionais, o tema da reforma agrária, que é, por sua vez, na lição de Carter (2010, p. 46), um instrumento de redistribuição da riqueza.

\section{A TEORIA DA JUSTIÇA DE JOHN RAWLS}

A teoria proposta por John Rawls (2008, p. 4), denominada justiça como equidade, estabelece que a justiça é a qualidade mais importante das instituições sociais, de sorte que, mesmo eficientes e bem organizadas, a injustiça das leis ou das instituições autoriza que elas sejam reelaboradas ou mesmo retiradas do sistema.

Nesse sentido, Sá (2015, p. 38) firma a ideia de que a liberdade dos indivíduos não pode ser superada por arranjos institucionais (constituição, lei e etc) injustos, ainda que o objetivo seja o bem estar da coletividade, funcionando a justiça como verdadeira guardiã da liberdade individual frente à vontade da maioria.

Para a constituição de sua teoria, acredita Brito Filho (2016, p. 35 e 39) que Rawls, especialmente no que toca aos princípios de justiça propostos, empresta significativa importância ao indivíduo, desautorizando que direitos básicos da pessoa sejam restringidos ou limitados sob a justificativa de isso ser imprescindível para a maximização da felicidade da maioria, repudiando que um "ser humano sobrepuje outro, condenando ainda desigualdades que importem em prejuízos aos demais, ou, ao menos, aos que são menos favorecidos”.

Percebe-se então que a proposta de Rawls é combater e afastar as concepções utilitaristas de justiça, pretendendo difundir a ideia de que todo ser humano é dotado de direitos invioláveis, os quais devem ser garantidos por um sistema justo, que contemple o respeito pela individualidade numa sociedade plural, com diferentes maneiras de se compreender a realidade e as necessidades de cada um para a constituição de uma vida digna.

A partir disso, o que se observa é que a teoria de Rawls (2008, p. 36) possui uma natureza deontológica, onde a noção do justo vem antes da noção de bem, entendido esse último como a "satisfação do desejo racional". Nesse particular, a interpretação de Gargarella (2008, p. 3) é a de que Rawls apresenta uma concepção não-consequencialista, pela qual a correção moral de um ato tem relação íntima com as qualidades dessa ação. 
Com efeito, dada a preocupação com o indivíduo e a prevalência do justo sobre o bem, Fleischacker (2006, p. 161) anota, entendendo ser uma das melhores sugestões de Rawls, que “a justiça só deve se ocupar da distribuição de 'bens primários' - bens necessários à busca de praticamente qualquer fim humano - e deve deixar de lado a questão de o que constitui o bem humano supremo".

Percebe-se, pois, que a missão primeira da justiça é realizar a distribuição dos bens básicos de todo ser humano, entendido como aqueles indispensáveis à concretização de qualquer projeto de vida boa e com dignidade.

Nesse campo, Brito Filho (2016, p. 45-46) entende que os bens primários referidos por Rawls não são os naturais (saúde, inteligência, vigor, imaginação e talentos naturais, os quais sofrem interferência das instituições, mas não são por elas distribuídos), e sim os bens primários sociais, que devem ser compreendidos como os bens fundamentais. Ainda para Brito Filho (2016, p. 245) bens primários "são todos os fundamentais, indicados a partir do artigo $5^{\circ}$, Constitucional, em conjunto que inclui os direitos e garantias individuais e coletivos, os direitos sociais, os direitos de nacionalidade e os direitos políticos".

Nessa medida, os bens primários sociais ${ }^{2}$ que são, segundo Rawls (2008, p. 110), aqueles que todo ser dotado de racionalidade persegue e que estão catalogados nas categorias de direitos e poderes, liberdades e oportunidades, renda e riqueza, devem ser distribuídos de maneira justa entre os indivíduos.

Assim, Rawls $(2008$, p. 8, 70) entende que o principal objeto da justiça é a estrutura básica da sociedade, isto é, a maneira como as instituições sociais relevantes (constituições políticas e os arranjos econômicos e sociais mais importantes) distribuem os direitos e os deveres fundamentais, estabelecendo ainda o compartilhamento das vantagens oriundas da cooperação social.

Nesse particular, interpretando as lições de Rawls, Brito Filho (2016, p. 36) acredita que o referido autor prende-se a um "ambiente limitado" - estrutura básica da sociedade - porque imagina que esse é o palco adequado para o desenvolvimento de sua teoria. Parte-se, portanto, de uma sociedade bem ordenada, na qual o bem de seus membros é perseguido, além dela ser efetivamente regulada por uma concepção pública de justiça (Rawls, 2008, p. 560).

\footnotetext{
${ }^{2}$ Rawls (2008, p.543) considera como o bem primário mais importante o auto-respeito, compreendido como: $i$ ) a convicção que a pessoa possui de que vale a pena realizar o seu projeto de vida; $i$ ) e a confiança que o indivíduo deposita em sua própria capacidade.
} 
Mais a frente, Rawls (2008, p. 66-67) apresenta a sua compreensão sobre instituição social como sendo o "sistema público de normas que define cargos e funções com seus direitos e deveres, poderes e imunidades e etc.”. Ele cita os seguintes exemplos de instituições, os julgamentos, os parlamentos, os mercados e os sistemas de propriedade, dentre outros, acreditando que os indivíduos que participam, de uma forma ou de outra, dessas instituições têm conhecimento do que as normas exigem deles e dos outros, assim como esses últimos também detém esse conhecimento.

Essas instituições são justas para Rawls (2008, p. 6), à medida que não realizam distinções injustificadas entre pessoas na atribuição de direitos e deveres fundamentais, assim como também quando as leis estabelecem um equilíbrio nas vantagens da vida social que estejam em conflito.

Observa-se, portanto, que esses arranjos institucionais precisam estar muito bem equilibrados e tareados para, na condição de objeto da justiça, terem capacidade de promoverem-na.

Até porque Rawls (2008, p. 4-5) advoga a ideia de que a sociedade funciona como um verdadeiro sistema equitativo de cooperação constituído para a promoção do bem dos seus membros, que são pessoas, em certa medida, autossuficientes, livres e iguais e que detêm as condições indispensáveis para a concepção de bem, além de possuírem um senso de justiça.

Nesse sentido, a liberdade e a igualdade de todos constituem as propriedades morais fundamentais e que podem ser representadas pela capacidade que todo cidadão possui para definir a sua concepção de bem, estabelecendo um senso de justiça.

Para Rawls (2008, p. 5), a sociedade funciona como uma grande estrutura que permite o desenvolvimento de cada um de seus membros, a partir do alcance de vantagens proporcionadas pela atuação de outros (indivíduos) na cooperação social. Todavia, apesar dessas vantagens, a sociedade também é marcada por conflitos, especialmente no que se refere à questão de como é feita a distribuição das vantagens produzidas com os maiores benefícios alcançados com a colaboração direta do indivíduo. Até porque, naturalmente, para atingir seus fins, cada indivíduo prefere uma quota maior de benefícios a uma menor.

Como solução para esse conflito, Rawls (2008, p. 5) propõe o estabelecimento de um conjunto de princípios que autorizem definir, dentre vários modos de organização social, um que formule a divisão de vantagens e um acordo sobre as parcelas distributivas apropriadas, permitindo, assim, que a sociedade se estabeleça de uma maneira bem ordenada. 
A definição desses princípios, aliás, na lição de Sá (2015, p.40), reproduzindo ensinamento de João Cardoso Rosas, é o objetivo da justiça - que difere do objeto da justiça visto acima.

Ademais, referidos princípios, segundo Rawls (2008, p.21-26), seriam escolhidos numa situação hipotética (imaginária), naquilo que chamou de "posição original" - "momento inicial" para Brito Filho (2016, p.39) - e sob o "véu da ignorância", de modo que, nesse cenário, os indivíduos desconheceriam as circunstâncias sociais e naturais que lhes afetariam e, por isso, referidos princípios deveriam ser escolhidos de maneira imparcial.

Com isso, o que Rawls deseja é mostrar como esses indivíduos chegariam a um consenso sobre os princípios de justiça; afinal, a ausência de informações sobre si mesmas e sobre sua situação garante que as pessoas da posição original não formulem princípios em benefício próprio, mas princípios gerais e de aplicação universal. O véu de ignorância possibilita que todos sejam convencidos pelos mesmos argumentos, de tal modo que as partes não têm como negociar no sentido usual.

Outra coisa importante a se dizer é que o indivíduo descrito por Rawls na posição original, para Gargarella (2008, p. 21), é um ser humano racional e preocupado consigo mesmo. Portanto, do ponto de vista do acordo inicial, supõe-se que as pessoas são seres racionais e, em geral, preferem ter mais e não menos bens primários sociais - direitos, liberdades e oportunidades, renda e riqueza, além do auto-respeito - como meios para melhor promover seus objetivos, já que não conhecem os pormenores do seu projeto de vida racional.

Nesse ponto, Brito Filho (2016, p. 40), explicando o indivíduo racional, afirma que esse sujeito, diante do leque de alternativas de que dispõe, tem capacidade de julgar as opções que lhes são ofertadas e escolher aquela que melhor atenda o seu plano de vida, satisfazendo os seus desejos, com mais chances de ser bem sucedido.

Com efeito, diante dessas premissas, deve-se dizer que, sob o véu da ignorância e na posição original, os princípios de justiça a serem escolhidos reclamariam: igualdade na atribuição dos direitos e deveres fundamentais (bens primários); e a compreensão de que desigualdades sociais e econômicas só podem ser consideradas justas se possibilitarem benefícios a todos.

E é justamente por isso que Gargarella (2008, p. 26), interpretando Rawls, ensina que “as violações de uma ideia estrita de igualdade são aceitáveis no caso de servirem para incrementar as parcelas de recursos em mãos dos menos favorecidos, e nunca de as diminuir". 
Assim, Rawls (2008, p. 73) sugere, como primeira formulação, os seguintes princípios que seriam adotados na posição original e sob o véu da ignorância:

Primeiro: cada pessoa deve ter um direito igual ao sistema mais extenso de iguais liberdades fundamentais que seja compatível com um sistema similar de liberdades para as outras pessoas.

Segundo: as desigualdades sociais e econômicas devem estar dispostas de tal modo que tanto (a) se possa razoavelmente esperar que se estabeleçam em benefício de todos como (b) estejam vinculadas a cargos e posições acessíveis a todos.

Mais a frente, Rawls (2008, p. 376), depois de indicar casos de prioridade, propõe a versão final dos princípios de justiça para instituições, nos seguintes termos:

\section{Primeiro princípio}

Cada pessoa deve ter um direito igual ao mais abrangente sistema total de liberdades básicas iguais que seja compatível com um sistema similar de liberdades para todos. Segundo princípio

As desigualdades econômicas e sociais devem ser dispostas de modo a que tanto:

(a) se estabeleçam para o máximo benefício possível dos menos favorecidos que seja compatível com as restrições do princípio de poupança justa, como

(b) estejam vinculadas a cargos e posições abertos a todos em condições de igualdade equitativa de oportunidades"

Primeira regra de prioridade (a prioridade da liberdade)

Os princípios de justiça devem ser dispostos em ordem lexical e, portanto, só se podem restringir as liberdades básicas em nome da própria liberdade. Existem dois casos:

(a) Uma liberdade menos extensa deve fortalecer o sistema total de liberdades partilhado por todos;

(b) Uma liberdade desigual deve ser aceitável para aqueles que têm menor liberdade. Segunda regra de prioridade (a prioridade da justiça sobre a eficiência e o bem estar) O segundo princípio de justiça precede lexicalmente o princípio da eficiência e o princípio da maximização da soma de vantagens; e a igualdade equitativa de oportunidades precede o princípio de diferença. Há dois casos:

(a) A desigualdade de oportunidades deve aumentar as oportunidades daqueles que têm menos oportunidades;

(b) Uma taxa elevada de poupança deve, pesando-se tudo, mitigar o ônus daqueles que carregam esse fardo.

Percebe-se, antes de mais nada, em relação aos dois princípios acima discriminados, que eles foram elaborados e dispostos numa ordem sequencial ou, como o próprio Rawls (2008, p. 51) chamou, numa "ordem serial ou léxica". Aqui, vale anotar que os dois princípios de justiça foram pensados numa sequência de prioridade lexicográfica, de sorte que por ela a liberdade não pode ser restringida (diminuída) para fins de se obter maiores vantagens sociais e econômicas. Sua redução somente está autorizada para se assegurar a manutenção de outras liberdades básicas.

Rawls (2008, p. 185) defende a prioridade da liberdade pela seguinte razão:

A prioridade da liberdade significa que, sempre que as liberdades fundamentais podem ser de fato instituídas, não é permitido trocar uma liberdade menor ou desigual por uma melhoria do bem estar econômico. É só quando as circunstâncias sociais não permitem a instituição desses direitos fundamentais que se pode consentir em sua limitação; e, mesmo assim, essas restrições só podem ser admitidas 
na medida em que forem necessárias para preparar o caminho para o momento em que não mais se justifiquem.

Comentando o pensamento Rawlsiano, Kymlicka (2006, p. 68) aponta a precedência da liberdade igual sobre a igual oportunidade, que, por sua vez, precede a ideia de recursos iguais, sem nunca perder de vista, todavia, que uma desigualdade somente é autorizada se ela beneficiar aqueles que se encontram em pior situação.

Brito Filho (2016, p. 42) critica a prevalência da liberdade, pois acredita que, não obstante ser elemento fundamental para a formação de uma sociedade democrática, ela não deve ser colocada à frente da igualdade, prioritariamente.

Pois bem, tendo em conta a ordem lexical, impende, neste momento, tecer breves comentários sobre o primeiro princípio de justiça, isto é, a liberdade.

Para Rawls (2008, p.74) as liberdades fundamentais, a exemplo da liberdade política, da liberdade de expressão e reunião, da liberdade de consciência e de pensamento, da liberdade individual, do direito à propriedade pessoal e a proteção contra prisão arbitrária, devem ser iguais.

E essas liberdades, que devem ser iguais para todos, não podem ser limitadas para fins de se privilegiar outros valores ou bens, mas apenas se forem indispensáveis para o fortalecimento do sistema total de liberdades iguais. Rawls (2008, p. 302-303) ensina que "Os dois princípios estão em ordem lexical, e portanto as exigências de liberdade devem ser atendidas primeiro. Até que isso seja alcançado, nenhum outro princípio entra em jogo".

Ocorre, todavia, que Rawls (2008, p. 75), expressamente, afasta do catálogo das liberdades, por não considerá-las fundamentais, a propriedade dos meios de produção ${ }^{3}$, a exemplo da terra. E isso tem impacto direto sobre os fins deste trabalho, à medida que dessa maneira não haverá que se falar em impossibilidade de se limitar o direito de propriedade da terra com o objetivo de se promover a diminuição das desigualdades sociais e econômicas, implementando-se, inclusive, o aumento da igualdade de oportunidade.

Pois bem, tendo em conta o afastamento da propriedade dos meios de produção da lista de liberdades fundamentais e, portanto, do campo inerente ao primeiro princípio de justiça, cabe, então, avançarmos para o segundo princípio da teoria Rawlsiana, que, em suma, conforme visto acima, combina o princípio da igualdade equitativa de oportunidades com o princípio de diferença.

\footnotetext{
${ }^{3}$ Mattos Neto (1988, p. 44-45) coloca a terra como um exemplo de bem de produção, haja vista que ela se destina, normalmente, à produção de outros bens e/ou permite a repartição de bens existentes. E, tudo isso, pode se dar com a ajuda ou não do homem.
} 
O segundo princípio é voltado para a distribuição de renda e riqueza e à estruturação dos cargos de autoridade e responsabilidade das instituições.

Brito Filho (2016, p. 44) afirma que por esse segundo princípio Rawls admite as desigualdades econômicas e sociais, contanto que isso promova um maior benefício aos menos favorecidos e que seja realizada em meio à igualdade de oportunidades.

Vale dizer que o segundo princípio da teoria da justiça, em verdade, está subdividido em dois: $i$ ) princípio da igualdade equitativa de oportunidades; ii) e o princípio da diferença.

Nesse sentido, para fins de explicar o primeiro deles, Sá (2015, p. 43) ensina que os que têm capacidades e habilidades semelhantes devem ter oportunidades iguais, o que representa segundo ele que as posições das carreiras abertas aos talentos não podem estar franqueadas aos indivíduos apenas sob o ponto de vista formal, mas também, e principalmente, sob o enfoque material, real.

Com efeito, o sistema de igualdade liberal proposto por Rawls (2008, p. 87-88) tenta corrigir eventuais desigualdades (injustiças) nas parcelas distributivas que sejam frutos de uma influência indevida de fatores moralmente arbitrários (talentos e origem social).

Por sua vez, o princípio da diferença, que segundo Kymlicka (2006, p. 68) orienta a distribuição dos recursos econômicos, serve como verdadeira concepção igualitária. Para Rawls (2008, p. 100) as desigualdades sociais e econômicas somente podem ser chanceladas se proporcionarem o máximo benefício para os menos favorecidos.

Reproduzindo lição de Álvaro de Vita, Brito Filho (2016, p. 45) ensina que o princípio de diferença corresponde a verdadeira ideia de igualdade de recursos ou de bens primários, buscando-se uma distribuição equitativa - que não significa necessariamente distribuição igual - dos recursos fundamentais, restando autorizadas as desigualdades apenas e tão somente quando elas puderem ser justificadas.

Nesse diapasão, Gargarella $(2008$, p. 26) afirma que “[...] as violações de uma ideia estrita de igualdade só são aceitáveis no caso de servirem para incrementar as parcelas de recursos em mãos dos menos favorecidos, e nunca de as diminuir".

Para Rawls (2008, p. 121), o princípio de diferença encara a distribuição dos talentos naturais, em certa medida, como um bem comum, haja vista que os favorecidos na distribuição desses fatores moralmente arbitrários só se podem deles beneficiar em circunstâncias que melhorem a situação dos menos afortunados. 
Pois bem, firmados todos esses pontos sobre a teoria de justiça proposta por Rawls, é de se dizer que a mesma é tida como uma referência acerca da discussão sobre justiça distributiva, pois introduziu ${ }^{4}$ a igualdade como ideal político, que, até então, era centrado apenas no elemento liberdade.

Nesse particular, aliás, Fleischacker (2006, p. 21 e 166) advoga que os dois princípios de justiça de Rawls correspondem à concepção moderna de justiça distributiva e que antes disso essa expressão era vazia de qualquer definição semelhante. Nessa concepção moderna, os indivíduos são merecedores de certos bens independentemente de seu caráter ou de algo que tenham realizado.

Assim, a justiça distributiva proposta por Rawls é do tipo igualitária, onde todos devem gozar dos mesmos bens básicos e fundamentais, sendo autorizada a desigualdade desde que seja para beneficiar os menos favorecidos.

Para Rawls (2008, p. 342) o problema central da justiça distributiva é a escolha de um sistema social que se compatibilize com os princípios de justiça, os quais, conforme já visto, se aplicam a estrutura básica da sociedade e regulam o modo como suas instituições mais importantes se combinam. Nesse sentido, o sistema deve ser estruturado de modo que a distribuição dos bens primários sociais seja justa.

Aqui, vale a pena anotar o ensinamento de Fleischacker (2006, p. 8) no sentido de que, modernamente, a concepção de "justiça distributiva" atribui ao Estado a tarefa de garantir que a propriedade seja distribuída por toda a sociedade e, assim, possibilitando que todos os indivíduos pertencentes àquela comunidade acessem determinados recursos materiais. Acrescenta ainda que a discussão sobre justiça distributiva gira em torno de se saber a quantidade de recursos que se deve garantir e em qual medida a interferência estatal é necessária para essa distribuição.

\section{A REFORMA AGRÁRIA}

Nesta seção será abordado o significado de reforma agrária, seus aspectos constitucionais e legais, sua condição de direito fundamental e de bem primário na Teoria da Justiça de Rawls. Além disso, também haverá espaço para se tratar acerca da teoria da função

\footnotetext{
${ }^{4}$ É importante deixar claro que até então as discussões filosóficas sobre teorias da justiça estavam restritas à discussão sobre liberdade. $\mathrm{O}$ único bem que se buscava distribuir era a liberdade.
} 
social da propriedade, do imóvel objeto de reforma agrária, dos beneficiários da reforma agrária e ainda dos instrumentos para a realização da reforma agrária no Brasil.

\subsection{O significado de reforma agrária}

Para Costa (2014, p. 74), reforma agrária significa uma verdadeira redistribuição da terra, não apenas uma alteração da estrutura fundiária e o modo pelo qual se distribui no espaço a propriedade da terra rural, mas também uma mudança na estrutura de posse e uso da terra por intermédio de uma modificação substancial no seu regime e com o advento de uma nova noção de propriedade, que deve ser caracterizada como um mecanismo de melhoria social não só para os que nela trabalham, mas também para toda a sociedade.

Costa (2014, p. 75) acredita também que por envolver aspectos dos mais variados assuntos (político, econômico, sociológico, histórico, dentre outros), a definição de reforma agrária depende, sobremaneira, do momento histórico e da filosofia política adotada naquela ocasião num dado país, havendo concepções restritas e amplas de reforma agrária. As primeiras propugnam apenas a redistribuição da propriedade, enquanto que as segundas orientam-se pela implementação de um conjunto de medidas. Assim, a depender das circunstâncias de momento, a reforma agrária pode significar: $i$ ) mera redistribuição da terra, exigindo uma política fundiária de planificação e organização com consequências de ordem ética e social; ii) ou, de outro lado, uma verdadeira transformação do sistema de propriedades/posses e de exploração da terra, com a extinção de latifúndios e minifúndios e a implantação de um sistema justo de propriedade, com o surgimento de um novo estatuto jurídico que discipline a matéria a partir da orientação do cumprimento de sua função principal e mediante uma política agrícola que abra espaço para o crédito e assistência técnica.

Para os fins deste trabalho, adotar-se-á a segunda concepção.

Mattos Neto (2013, p. 12), filiando-se à ideia de reforma agrária ampla ou integral, define-a como:

[...] a reestruturação da divisão do solo motivada pela concentração de terras em poder de poucos, que é a reforma fundiária, mas também a implementação e redefinição de políticas agrícolas e demais políticas públicas vinculadas ao setor que visem à fixação do homem no campo e seu desenvolvimento, como por exemplo, o incentivo fiscal, o crédito agrícola, a construção de infraestrutura com saneamento básico, transporte, energia, escolas, postos de saúde, armazéns e silos, estradas vicinais e etc.

Como o programa deve ser integrado a outras ações e políticas governamentais, chama-se reforma agrária integral. 
Sobre o assunto, interessante também a definição de Rocha (2010, p. 316):

a reforma agrária se exterioriza pela intervenção do Estado, no sentido de redimensionar a estrutura agrária do país, visando a melhor distribuição de terras a todos os que dela necessitam, e o aumento da produtividade, promovendo a efetivação de justiça social, e colaborando com a erradicação da pobreza e demais objetivos previstos no artigo $3^{\circ}$ da Constituição Federal de 1988, tidos como objetivos fundamentais da República Federativa do Brasil.

A Lei $\mathrm{n}^{\circ} 4.504 / 64$ (Estatuto da Terra) definiu, logo no seu artigo $1^{\circ}, \S^{\circ}$, o conceito de reforma agrária, estabelecendo como tal "o conjunto de medidas que visem a promover melhor distribuição da terra, mediante modificações no regime de sua posse e uso, a fim de atender os princípios de justiça social e ao aumento de produtividade".

Diante disso, extrai-se que o termo reforma agrária reclama uma profunda alteração na estrutura agrária existente, com a formação de um novo ideal para a relação ser humano-terraprodução, a partir de um novo conceito para o direito de propriedade, fundado na utilização econômica da terra, com vantagem individual e social e, ainda, com respeito agroambiental, substituindo-se o latifúndio e o minifúndio por um sistema mais justo de distribuição de propriedade, tudo para fins de atender os menos favorecidos e ao aumento da produtividade.

É imperioso deixar claro que o uso inadequado ${ }^{5}$ da terra traz embaraços e dificuldades ao desenvolvimento socioeconômico, o que dificulta o bem estar dos indivíduos, sobretudo do campesino, exigindo-se, assim, a implementação da reforma agrária como um processo de reestruturação da propriedade da terra, a fim de que: $i$ ) explorada de maneira racional, alcance a maior produtividade possível, permitindo a realização de uma melhor qualidade de vida e bem estar da sociedade; ii) e possa servir como instrumento de combate à concentração fundiária, proporcionando justiça social ${ }^{6}$ (distributiva) com o acesso dos menos favorecidos à terra.

Nesse sentido, o que se observa é que o conceito de reforma agrária adotado pela legislação e também pela doutrina nacional se aproxima bastante da concepção da justiça como equidade de John Rawls e de sua justiça distributiva, à medida que considera a terra como um bem básico e fundamental, sendo que qualquer desigualdade na sua distribuição deve ser para beneficiar os menos favorecidos.

\footnotetext{
${ }^{5}$ Mattos Neto (1988) entende que o uso adequado passa pela utilização econômica da área, com racionalidade, a partir de um cultivo eficiente (respeitando-se a aptidão natural do solo com utilização de instrumento e tecnologia agrícola) e de uma exploração correta (observando-se as normas agrárias, trabalhistas, previdenciárias e ambientais), em área de terra que não se caracterize nem como latifúndio e nem como minifúndio.

${ }^{6}$ Fleischacker (2006, p.3) coloca como sinônimos os termos justiça distributiva e justiça social.
} 


\subsection{Aspecto constitucional e legal}

Antes de mais nada é importante deixar registrado que a Constituição da República de 1988 (CR/88) garante, expressamente, o direito de propriedade privada (artigo 5 ${ }^{\circ}, \mathrm{XXII}$ ), embora não lhe confira o caráter de absoluto, uma vez que o condicionou ao cumprimento da sua função social (artigo $5^{\circ}, \mathrm{XXIII).}$

A Lei Maior reservou um capítulo inteiro (Capítulo III do Título VII) para tratar da reforma agrária, fixando no seu artigo 184 que compete, exclusivamente, à União promover a desapropriação de imóvel que não esteja cumprindo a sua função social. Anotou também que a indenização será prévia e justa e em títulos da dívida agrária ${ }^{7}$, com cláusula de preservação do valor real.

O Texto Constitucional (artigo 184, $\$ 4^{\circ}$ ) determinou ainda que a Lei Orçamentária fixe anualmente o volume total de títulos da dívida agrária e o montante de recursos para atender ao programa de reforma agrária no exercício.

Mattos Neto (2013, p. 13) encara essa exigência como um golpe constitucional contra a reforma agrária, pois isso, segundo ele, facilita a ação dos setores contrários à efetivação da reforma, já que possibilita a barganha política.

O artigo 185 da CR/88 exclui qualquer possibilidade de desapropriação para fins de reforma agrária da pequena e média propriedade rural - desde que seu proprietário não possua outra - e da propriedade produtiva, a quem deve ser dado tratamento legislativo especial.

No âmbito infraconstitucional, o Estatuto da Terra, no artigo $2^{\circ}, \S 2^{\circ}$, estipula que o acesso à propriedade da terra é um dever (obrigação) do Estado (poder público) e isso deve ser realizado preferencialmente nas regiões onde o trabalhador rural habita. Essa exigência legal está em fina sintonia com a justiça distributiva proposta por John Rawls, que é do tipo é do tipo igualitária, onde todos devem gozar dos mesmos bens básicos e fundamentais, sendo autorizada a desigualdade desde que seja para beneficiar os menos favorecidos.

O artigo 16 do mesmo Diploma Legal estabeleceu que o objetivo da reforma agrária é criar um sistema de relações entre o homem, a propriedade rural e o uso da terra que autorize a promoção da justiça social, o progresso e o bem estar do trabalhador, além do desenvolvimento econômico, com a extinção progressiva do minifúndio e do latifúndio.

\footnotetext{
${ }^{7}$ Segundo o $§ 1^{\circ}$ do artigo $184 \mathrm{da} C R / 88$, as benfeitorias necessárias e úteis serão indenizadas em dinheiro e não em títulos da dívida, reservados apenas para a terra objeto da desapropriação.
} 


\subsection{A reforma agrária como direito fundamental e como um bem primário na Teoria da} Justiça de Rawls

Para Duarte (2011, p. 47), os direitos fundamentais estão ligados aos bens jurídicos básicos da humanidade e a melhor forma de conceituá-los seria por intermédio da análise de sua fundamentalidade, decorrendo daí a importância da sua proteção formal e material.

$\mathrm{Na}$ fundamentalidade formal, vinculada ao direito constitucional positivo, há quatro características a serem destacadas: $i$ ) as normas fundamentais são postas no ápice da ordem jurídica; $i$ ) por serem normas constitucionais estão submetidas aos procedimentos agravados de revisão; iii) constituem-se como limites materiais à revisão; iv) servem como diretrizes matérias para atuação dos Poderes constituídos.

Por sua vez, na fundamentalidade material, Duarte (2011, p. 49), sustentado em Alexy, afirma que pelos direitos fundamentais e pelas normas proclamadoras de direitos fundamentais tomam-se decisões sobre a estrutura básica do Estado e da comunidade.

Com efeito, ainda segundo Duarte (2011, p. 49), a fundamentalidade material é indispensável, pois a ideia de fundamentalidade não pode ser restrita ao seu aspecto formal, seja porque apenas a concepção material pode servir de base para a proteção de direitos também fundamentais, mas não protegidos formalmente, seja para o emprego aos direitos fundamentais materiais de recursos jurídicos previstos apenas para os direitos fundamentais formais.

A fundamentalidade material também é importante para assegurar a possibilidade de ingresso de novos direitos ainda não reclamados e desvelados, mas que tenham as características de fundamentais, até pela característica de incompletude da fundamentalidade formal.

Nesse sentido, Costa (2014, p. 103) acredita ser a reforma agrária um direito fundamental - de fundamentalidade material-, porque importa em decisões sobre a estrutura do Estado e da sociedade, mais especificamente sobre o surgimento de um novo conceito de propriedade, lastreado na função social e objetivando contribuir para o desenvolvimento nacional, diminuição da pobreza e desigualdades sociais.

Com a alteração no conceito de propriedade, esse direito que antes era tido como absoluto e ilimitado passou a ser submetido aos interesses sociais e coletivos, por intermédio do princípio da função social. Essa nova configuração do direito de propriedade, conforme já 
dito acima, foi consolidada na Constituição da República de 1988, artigo 5º incisos XXII e XXIII.

A partir dessa nova formatação, a propriedade assume a condição de bem voltado à geração de riquezas e frutos que deverão ser usufruídos não só pelo seu titular, mas também pela coletividade. Percebe-se aqui uma aproximação com o princípio da diferença de Rawls.

Para Costa (2014, p.104), a incorporação da função social ao conceito de propriedade implica num uso racional e equilibrado do bem (objeto do direito), objetivando proporcionar resultados positivos para toda a comunidade. E tanto isso é verdade que a CR/88, no Título da Ordem Econômica e Financeira, artigo 170, condiciona a atividade econômica à finalidade de se assegurar a dignidade humana, sob as orientações da justiça social, observando-se, dentre outros, os princípios da propriedade privada e o da função social.

Nesse sentido, o que se tem é uma verdadeira imposição constitucional, de sorte que o proprietário não detém nenhuma margem para descumprimento, caracterizando-se, pois, a função social como um dever e a sua inobservância dá causa à desapropriação para fins de reforma agrária. Resta claro, assim, que o uso da terra deve beneficiar a todos, inclusive os menos favorecidos.

Ainda nas lições de Costa (2014, p. 105), os princípios da ordem econômica procuram harmonizar e compatibilizar os interesses privados (propriedade privada) aos públicos (função social), figurando a reforma agrária como um instrumento importante para a efetivação desse paradigma, conferindo ao Estado o poder-dever de implementar a renovação do conceito de propriedade, importando em mudanças na estrutura do Estado e da sociedade, assegurando-se a justiça social e o respeito à dignidade humana.

Nesse diapasão, a reforma agrária se caracteriza como um direito fundamental e, assim, nas lições de Brito Filho (2016, p. 45-46), um bem primário social, por isso, segundo Kymlicka (2006, p. 82), objeto de distribuição pelas instituições sociais (Estado e seu sistema público de normas).

\subsection{A teoria da função social da propriedade}

Conforme já visto acima, não obstante o Texto Constitucional (artigo $5^{\circ}$, inciso XXII, e artigo 170) garantir o direito de propriedade, ele impõe limites a esse direito, à medida que estabelece como dever do proprietário o respeito ao princípio da função social. 
No trecho relativo à reforma agrária, a CR/88, nos artigos 184 e 186, disciplinou que a União é o ente federativo competente para realizar a desapropriação por interesse social para fins de reforma agrária de imóveis que não atendam o princípio da função social, com aproveitamento racional e adequado do potencial econômico, utilização dos recursos naturais com a preservação do meio ambiente, respeito à legislação do trabalho e o bem estar dos proprietários e dos trabalhadores.

Por todo esse tratamento conferido pela $\mathrm{CR} / 88$, ao direito de propriedade foi incorporado o dever jurídico do titular de agir em busca do interesse coletivo. Em outras palavras: o direito subjetivo do proprietário foi submetido e está condicionado ao interesse comum, exigindo-lhe o cumprimento de uma função social voltada ao interesse da coletividade.

Assim, o que se observa, em verdade, é a funcionalização da propriedade aos valores econômicos, sociais e existenciais.

A propriedade representa, pois, uma relação entre o sujeito e o bem, cujo exercício em prol da sociedade é de interesse público, configurando-se como um verdadeiro direito-meio e não um direito-fim, não tendo nenhuma garantia em si mesma, só se justificando como ferramenta de viabilização de valores fundamentais, dentre os quais sobressai o da dignidade da pessoa humana.

Destaca-se, ainda nesse ponto, as lições de Mattos Neto (2010, p. 37) para quem a funcionalidade serviu para adequar e abrigar o privatístico direito de propriedade à concepção social do mundo atual, onde a propriedade, além das faculdades que lhes são inerentes, também possui atribuições, limitações e deveres, impondo ao titular do direito uma responsabilidade social de caráter positiva, à medida que o proprietário ou possuidor deve praticar atos positivos de exploração econômica.

De se dizer que além do aspecto positivo (obrigações de fazer, como de tonar economicamente viável e produtiva a propriedade), a função social também impõe ao proprietário condutas negativas (abstenção, como não causar dano ao meio ambiente).

Nesse passo, pelo Texto Constitucional, o cumprimento da função social da terra está condicionado à observância de 03 (três) dimensões, a saber: econômica, ambiental (ecológica) e social.

Nas lições de Torres (2010, p. 241-260), a primeira delas, a econômica, está diretamente ligada ao aspecto produtivo, com exploração eficiente e capaz de contribuir direta ou 
indiretamente para o incremento e o desenvolvimento econômico regional, com a produção e geração de renda para seus proprietários/possuidores e empregados, pagamento de tributos para os entes federativos e etc.

Já a dimensão ambiental, por sua vez, segundo Maniglia (2013, p. 41), está intrinsecamente ligada à observância e consequente cumprimento das normas de preservação ambiental e de exploração dos recursos naturais, sobretudo os não renováveis. Aqui, deve-se perseguir a exploração sustentável dos meios de produção, respeitando-se as limitações naturais para que as futuras gerações não sejam prejudicadas e/ou penalizadas por uma exploração irracional e desmedida e que provoque o esgotamento da riqueza natural.

Nesse ponto, vale o registro de que para a Lei no 8.629/93 (Lei da Reforma Agrária), artigo $9^{\circ}, \S 3^{\circ}$, a conservação do meio ambiente está condicionada à manutenção das características próprias do meio natural e da qualidade dos recursos ambientais na medida necessária para se assegurar a continuidade do equilíbrio ecológico e da saúde da propriedade e vida das comunidades vizinhas.

Por fim, o último elemento da função social da terra, qual seja, a dimensão social, exige que o proprietário/possuidor cumpra fielmente as normas trabalhistas e previdenciárias, gerando assim o bem estar social entre os homens e a consequente paz entre eles.

A funcionalidade instituída constitucionalmente, no dizer de Maniglia (2013, p.34), tem como objetivo a utilização da propriedade para a própria finalidade a que ela se destina (produção de alimentos e de riqueza, moradia, trabalho e bem estar), o que não gera contraposição entre os interesses individuais e coletivos. Ao contrário, eles são inteiramente compatíveis e possíveis de serem harmonizados.

Vê-se, pois, claramente que a propriedade continua a ser direito garantido, porém, cabe ao titular desse direito um dever vinculado a um elemento econômico, a um elemento ambiental e a um outro social, considerando que estes foram os tópicos desenhados no artigo 186 da CR/88 para expressar o cumprimento da função social.

\subsection{Imóvel objeto de reforma agrária}

A reforma agrária tem como palco o campo, logo o seu objeto é, indubitável e exclusivamente, o imóvel rural. 
O imóvel rural, aliás, deve ser compreendido, segundo o artigo $4^{\circ}$, inciso I, do Estatuto da Terra, a partir do critério da destinação, ou seja, é considerado como tal o imóvel que, independentemente da sua localização, é voltado à exploração de atividade agrária.

Pois bem, estão sujeitas à desapropriação para fins de reforma agrária as propriedades rurais que não estejam cumprindo a sua função social, nos termos do artigo 186 da CR/88 e artigo $9^{\circ}$ da Lei 8.629/93.

A CR/88, contudo, conferiu a característica de não ser suscetível à reforma agrária a pequena e média propriedade rural - desde que seu proprietário não possua outra - e a propriedade produtiva.

Assim, importa definir cada uma dessas espécies de propriedade.

A Lei 8.629/93, artigo $4^{\circ}$, inciso II, conceitua a pequena propriedade como o imóvel rural de área compreendida entre 1 (um) e 4 (quatro) módulos fiscais.

$\mathrm{O}$ inciso seguinte diz que a média propriedade é aquela de área superior a 4 (quatro) e até 15 (quinze) módulos fiscais.

Vale registrar que esses dois tipos de imóveis rurais somente serão insuscetíveis à expropriação para fins de reforma agrária se o seu proprietário não possuir outra propriedade. Para Costa $(2014,142)$, essa condicionante deixa claro a necessidade da exploração do imóvel por seu proprietário, enfatizando o trabalho na terra pelo dono, seja de qual forma for.

Registre-se, nesse particular, que a lei da reforma agrária não se preocupou com a função social da propriedade, não obstante a fundamentalidade desse princípio - consoante visto acima -, restringindo-se a anotar como critérios o número de módulos fiscais e de o proprietário não possuir outra propriedade. Aqui, entendemos que há um descolamento entre a previsão legal e a teoria da justiça de John Rawls, uma vez que, nesse ponto, inviabiliza-se a realização do princípio da diferença, à medida que não se tem como garantir que as desigualdades sociais e econômicas daí decorrentes proporcionarão o máximo benefício para os menos favorecidos, haja vista que a propriedade não fica obrigada a realizar aproveitamento racional e adequado, cumprindo a sua destinação econômica e social.

Além da pequena e da média propriedade rural, também são insuscetíveis de expropriação para fins de reforma agrária a propriedade produtiva.

A Lei da Reforma Agrária, artigo 6 ${ }^{\circ}$, diz que a propriedade produtiva é "aquela que, explorada econômica e racionalmente, atinge, simultaneamente, graus de utilização da terra e de eficiência na exploração, segundo índices fixados pelo órgão oficial competente". 
Segundo o $\S 1^{\circ}$ do artigo acima referido, a propriedade produtiva deverá apresentar Grau de Utilização da Terra (GUT) igual ou superior a $80 \%$. O $\S 2^{\circ}$, por sua vez, determina que é preciso atingir um grau de eficiência na exploração (GEE), que deverá ser igual ou superior a $100 \%$.

Nesse particular, vale o registro de que a definição legal restringiu-se aos aspectos econômicos, tornando dispensável o cumprimento dos demais elementos da função social (dimensão social e ecológica), contrapondo-se a sua fundamentalidade e, em consequência, se afastando da teoria da justiça de John Rawls.

\subsection{Beneficiários da reforma agrária}

De acordo com o artigo 189 da CR/88 c/c artigo $4^{\circ}$, VII, do Estatuto da Terra, são denominados beneficiários da reforma agrária aqueles que venham a adquirir lotes ou parcelas em áreas destinadas à reforma agrária ou à colonização pública ou privada.

A Lei da Reforma Agrária, artigo 19, previu que a distribuição da área desapropriada, por meio de títulos de domínio ou concessão de uso, observará a seguinte ordem de preferência: i) ao desapropriado; ii) aqueles que trabalham no imóvel desapropriado como posseiros, assalariados, parceiros ou arrendatários; iii) aos ex-proprietários de áreas alienadas para fins de pagamento de débitos originados de operações de crédito rural; $i v$ ) aos que trabalham como posseiros, assalariados, parceiros ou arrendatários, em outros imóveis; $v$ ) aos agricultores cujas propriedades não alcancem a dimensão da propriedade familiar; vi) aos agricultores cujas propriedades sejam, comprovadamente, insuficientes para o sustento próprio e o de sua família.

O parágrafo único do dispositivo acima discriminado prevê que, dentro da ordem de preferência, terão prioridade os chefes de famílias numerosas, cujos membros se proponham a exercer a atividade agrícola na área a ser distribuída.

Segundo Costa (2014, p. 161), qualquer pessoa que se enquadre numa das hipóteses previstas da Lei da Reforma Agrária será beneficiário.

De modo geral, os beneficiários apontados pela legislação compõem um grupo social desfavorecido econômica e socialmente e, assim, a previsão legal se harmoniza com a teoria da justiça de John Rawls, pelo menos neste campo. 


\section{CONSIDERAÇÕES FINAIS}

O presente estudo buscou analisar em que medida a política de reforma agrária, com assento constitucional, favorece uma noção de justiça distributiva nos moldes do pensamento liberal igualitário de John Rawls.

Após toda a exposição, creio que é possível responder afirmativamente ao problema apresentado, isto é, a reforma agrária pode ser encarada como um instrumento de justiça distributiva nos moldes propostos por John Rawls.

Diz-se isso, porque a justiça distributiva idealizada por Rawls é do tipo igualitária, onde todos devem gozar dos mesmos bens básicos e fundamentais, sendo autorizada a desigualdade desde que seja para beneficiar os menos favorecidos.

Essa concepção de "justiça distributiva" atribui ao Estado a tarefa de garantir que a propriedade seja distribuída por toda a sociedade, possibilitando, assim, que todos os indivíduos pertencentes àquela comunidade acessem determinados recursos, os bens primários básicos, cuja distribuição deve ser justa.

Ora, o conceito de reforma agrária adotado pela legislação se aproxima bastante dessa concepção de justiça distributiva, à medida que considera a terra como um bem básico e fundamental, sendo que qualquer desigualdade na sua distribuição deve ser para beneficiar os menos favorecidos.

Um exemplo claro da harmonia entre a previsão legal e a doutrina de Rawls é a previsão constante no artigo $2^{\circ}, \S 2^{\circ}$, do Estatuto da Terra, que estabelece que o acesso à propriedade da terra é um dever (obrigação) do Estado (poder público).

Há, é verdade, pontos da legislação que se contrapõem à ideia Rawlsiana, a exemplo do comando constitucional (artigo 185) que torna insuscetível de desapropriação para fins de reforma agrária determinadas propriedades, mas que não têm o condão de negar a associação entre a referida teoria e a reforma agrária.

Por tudo isso, dada ainda a condição da reforma agrária caracterizar-se como um direito fundamental, importando na ressignificação do conceito de propriedade, agora lastreado na função social e objetivando contribuir para o desenvolvimento nacional, diminuição da pobreza e desigualdades sociais, e por isso está alinhada à noção de justiça distributiva nos moldes do pensamento liberal igualitário de John Rawls. 


\section{REFERÊNCIAS}

BRITO FILHO, José Claudio Monteiro de. Ações Afirmativas. $4^{\mathrm{a}}$ ed. São Paulo: LTr, 2016.

CARTER, Miguel. Desigualdade social, democracia e reforma agrária no Brasil. In: Combatendo a desigualdade social: O MST e a reforma agrária no Brasil. Tradução de Cristina Yamagami. $1^{a}$ reimpressão. São Paulo: Editora UNESP, 2010.

COSTA, Rosalina Moitta Pinto da. O direito fundamental à reforma agrária e seus instrumentos de concretização. Porto Alegre: Núria Fabris Ed., 2014.

DUARTE, Leonardo de Farias. Obstáculos econômicos à efetivação dos direitos fundamentais sociais. Rio de Janeiro: Renovar, 2011.

FLEISCHACKER, Samuel. Uma breve história da justiça distributiva. Tradução de Álvaro de Vita. São Paulo: Martins Fontes,2006.

GARGARELLA, Roberto. As teorias de Justiça depois de Rawls: um breve manual de filosofia política. Tradução de Alonso Reis Freire. São Paulo: Martins Fontes, 2008.

KYMLICKA, Will. Filosofia política contemporânea: uma introdução. Tradução Luis Carlos Borges; revisão da tradução Marylene Pinto Michael. São Paulo: Martins Fontes, 2006.

MATTOS NETO, Antônio José. A posse agrária e suas implicações jurídicas no Brasil. Belém: Cejup, 1988.

2010.

Estado de direito agroambiental brasileiro. 1 ed. São Paulo: Saraiva,

Garantia do direito à propriedade agrária. In: In: BARROSO, Lucas Abreu et al (Org.). O direito agrário na Constituição. 3 ed., rev. atual., e ampl. Rio de Janeiro: Forense, 2013. p. 1-23.

RAWLS, John. Uma Teoria da Justiça. Tradução Jussara Simões. $3^{\text {a }}$ ed. São Paulo: Martins Fontes, 2008.

ROCHA, Ibraim et al. Manual de Direito Agrário Constitucional: Lições de direito agroambiental. Belo Horizonte: Fórum, 2010.

SÁ, João Daniel Macedo. Direito de Propriedade e justiça distributiva no Brasil: ampliação das capacidades como forma de combater a pobreza rural. 2015. $214 \mathrm{f}$. Tese (Doutorado). Universidade Federal do Pará. 2015.

TORRES, Marcos Alcino de Azevedo. A propriedade e a posse: Um confronto em torno da função social. 2 ed. Rio de Janeiro: Lumen Juris, 2010. 